\title{
EL SEMINARIO, COMUNIDAD FORMATIVA
}

DOI: https://doi.org/10.52039/seminarios.v63i219.91

ANTERO PASCUAL RODRÍGUEZ*

«El Seminario, antes que un edificio, es una comunidad formativa» (Ratio 188). Sin duda, el sentido del Seminario radica en entender la expresión "comunidad formativa», que constituye el eje radical que sostiene y da sentido al mismo. En lo demás, la consideración de unir varios seminarios o considerar propuestas de comunión entre varias diócesis pueden ser aspectos a considerar, si bien el sentido es «garantizar una comunidad formativa» ${ }^{1}$.

Por ello la propuesta de este artículo será la de llegar a entender esta expresión que, a mi juicio, es la que da sentido al proceso de formación sacerdotal en el Seminario.

La reflexión que propongo en las siguientes páginas nace desde la actual situación social y religiosa de donde vienen los candidatos, la importancia de respetar y promover la genuina identidad y necesaria cohesión del clero diocesano secular, las carencias educativas derivadas, en no pocos casos, de la crisis de la familia, de la escuela y de la insuficiente iniciación cristiana.

Finalmente, es muy importante tutelar la idoneidad afectiva de los candidatos, cuyo equilibrio y maduración son condicionantes para su estabilidad psíquica y para la correcta imagen pública del clero secular. No se puede ignorar la problemática que ocasiona la inestabilidad afectiva, tan presente en nuestro tiempo, y la necesidad de prevenir y evitar, en lo posible, casos problemáticos en el terreno de la vida afectiva/sexual, así como en el género de vida personal y comportamiento social. Junto al bien de las personas, también es necesario cuidar la identidad en el correcto equilibrio entre el ser y hacer del sacerdote en el contexto de la sociedad actual.

* Rector del Seminario Metropolitano de Sevilla.

1. La referencia central del Seminario entendido como "comunidad formativa» no tiene únicamente un sentido pastoral, sino que también aparece en el Código de Derecho Canónico en su canon 237. 
1. LA FORMACIÓN DE UN SACERDOTE: ¿EDUCACIÓN PROFESIONAL O EXPERIENCIA DE CONVERSIÓN? IDENTIDAD: ¿CAPACITACIÓN O IDONEIDAD?

El sacerdocio, más que un rol, es un estado de vida. El sacramento del Orden «imprime carácter», lo que significa que su eficacia se da en un plano ontológico. No obstante, cada vez se hace más difícil especificar aquello que en este plano, no en el de las tareas, distingue al sacerdote ordenado del sacerdocio bautismal. El sacerdote ejerce un rol, vale decir, realiza funciones y cuenta con determinadas atribuciones, y en ese sentido, puede ser asimilado en equivalencia a cualquier profesional. De hecho, gran parte del tiempo, los seminaristas lo ocupan en estudios de tipo universitario, organizados en torno a una malla curricular. Es quizás este el terreno donde se ha generado más debate, y se han intentado implementar algunas innovaciones en ciertos seminarios y centros de formación. Algunos formadores y rectores, preocupados por la disminución de vocaciones y por los acelerados cambios culturales y de estilo de vida -en especial en las áreas urbanas-, se preguntan si son pertinentes los contenidos entregados, si no hubiese que agregar otros cursos, etc. Dicho a las claras, si el sacerdocio es un oficio, es correcto e importante preguntarse por los cambios y por los desafíos del contexto cultural emergente, por las expectativas de los fieles, y tratar de responder a las necesidades de los tiempos. Cabe preguntarse: ¿qué tareas le son inherentes al sacerdote y cuáles delegables? ¿Qué habilidades, actitudes y conocimientos debería poseer un seminarista, y pedagógicamente, cuáles son los métodos más eficientes para desarrollarlos?

Ahora bien, la mayoría de los documentos, y de modo particular la nueva Ratio, no comprenden el ministerio sacerdotal en términos de un oficio, sino que en su parte central y radical habla de la vida e identidad de los presbíteros. Eso quiere decir, que la formación de un sacerdote no se puede agotar en un enfoque de tipo profesionalizante. Se espera que el paso por el seminario signifique la internalización de ciertas actitudes, normas y valores que toquen la identidad misma del futuro sacerdote. En ese sentido, podemos perfectamente aplicar lo que sabemos acerca de los procesos de socialización para entender la otra cara de la formación sacerdotal.

Para los sociólogos, la socialización es el proceso a través del cual una determinada agrupación social logra reproducirse, transmitiendo a los nuevos miembros aquellas normas y principios necesarios para la continuidad del sistema. La socialización va haciendo «previsible» a la persona 
y ajustada a sus objetivos, lo que permite el funcionamiento normal de dicha agrupación. Para los psicólogos, la socialización es el proceso a través del cual los individuos adquieren aquellas habilidades necesarias para adaptase y progresar en un determinado contexto social. En ambos puntos de vista, se entiende que la socialización marca al individuo con el sello propio del grupo social del que se trate, y por lo tanto está muy vinculada al desarrollo de la propia identidad como identidad social.

Es legítimo preguntarse si bastan la formación de tipo profesional y un intenso proceso de socialización para formar un sacerdote. Además de invocar la acción del Espíritu sobre los futuros sacerdotes, ¿puede el seminario intentar ofrecer una experiencia de desarrollo personal y espiritual capaz de habilitar verdaderos «pastores de almas»? La Ratio, como elemento indispensable para la formación sacerdotal, contiene claves fundamentales sobre los distintos aspectos de la vida de los seminarios y de la formación, sobre su organización, sobre la necesidad de revisar los estudios eclesiásticos a fin de abrir la inteligencia de los alumnos y prepararlos para dialogar con los hombres de su época, sobre la necesidad de revisar los métodos didácticos, sobre el fomento de la educación pastoral, etc.

Así, la importancia de la formación del sacerdote no es sólo la adquisición de conocimientos, eso es muy pobre para definir lo que es el paso por el seminario. Lo mismo ocurre con el proceso de socialización, de internalización de normas, valores y creencias, y de identificación del sacerdote con Cristo. Nos cuesta encontrar lo propio del sacerdote en sus funciones, como también en su estilo de vida. Si seguimos la afirmación de que los sacerdotes no podrían ser ministros de Cristo si no fueran testigos y dispensadores de una vida distinta de la terrena, ni podrían tampoco servir a los hombres si permanecieran ajenos a la vida y condiciones de los mismos, tenemos que pensar que, en parte, lo que constituye al sacerdote es una experiencia que implica traspasar un cierto umbral que los hace testigos de una vida distinta y a la vez los identifica con el mismo Señor como guías de otros en esta aventura.

Ahora bien, si seguimos hasta las últimas consecuencias esta afirmación que se repite en los documentos, en las palabras de los formadores y de los mismos seminaristas, de que el sacerdote es un nuevo Cristo, no podemos dejar de pensar que dicha experiencia corresponde a un cierto tipo de liberación de sí por medio de la propia muerte, que tal como lo anticipábamos, da un sentido más pleno a la noción de mortificación. Desde esta perspectiva podemos entender las palabras de san Pablo: «Os invito, 
hermanos, por la misericordia de Dios, que os entreguéis vosotros mismos como sacrificio vivo y santo que agrada a Dios: ese es nuestro culto espiritual» (Rom 12, 1). Si es así, los formadores deberían aprender a ejercitar la frustración bien hecha, a ser lo suficientemente elusivos como para dejar a cada seminarista en la soledad de su proceso espiritual sin ofrecer las respuestas antes de tiempo. Eso, siempre y cuando se adhiera a un modelo de formación que supone el camino del anonadamiento y de la experiencia de Dios.

Actualmente es fundamental tener en cuenta que la encarnación carece de efecto o de significación para nuestros contemporáneos si es mera historia; la encarnación es una «verdad salvífica» sólo si es perenne, una revelación de un acontecimiento atemporal que acompaña al ser humano. Es decir, se trata de una relación con el misterio que se actualiza en cada cristiano lo que le da sentido al Evangelio, y no al revés, se trata de hacer de la encarnación y su efecto más drástico, la muerte, palabra viva, y eso desafía a toda pedagogía en el seminario.

En suma, podemos distinguir tres áreas, que se superponen, en la formación del sacerdote: la profesional, la vinculada a su resocialización y la dimensión de conversión espiritual. Las tres son importantes, pero es la última la que da el sentido a las otras dos. Así también, es la más descuidada y difícil de hacer operativa. La vocación sacerdotal tiene un carácter místico. Sólo en la medida en que la experiencia de Dios persiste en el tiempo es posible una perseverancia "correcta», y no un producto de factores secundarios, compensatorios, como la gratificación de un trabajo social o la autorrealización como individuo.

La pregunta fundamental que surge como desafío es entonces: cómo puede el seminario combinar estas tres áreas y promover espacios para la experiencia de Dios; y además, con qué pedagogía y con qué estructuras se puede hacer esto.

\section{PEDAgogía de LA FORMACIÓN: MOTIVACIONES ASOCIADAS A LA VOCACIÓN SACERDOTAL}

En su origen, discernimiento, formación y fidelidad ministerial la vocación sacerdotal tiene en el carácter sobrenatural su categoría principal. Mas esto no está en disputa con las categorías naturales, es decir, con aquello que es propio de cada individuo y lo que puedan aportar las ciencias. En ese sentido, es válido realizar un análisis de las motivaciones que acompañan la decisión de ingresar al Seminario. 
a) El cristiano como un hombre libre; el sacerdote como maestro de la libertad

Como fuente primera, no podemos dejar de buscar pistas en el Evangelio mismo respecto de la invitación que Jesús nos hace a cada uno, y de lo que puede ser el papel y el perfil de un sacerdote. Ciertamente esto se ha hecho, pero el Evangelio siempre se nos ofrece como una vertiente inagotable, cuya lectura cambia según los tiempos y según el ángulo desde el cual la hagamos. En este caso, lo vamos a hacer teniendo como eje el tema de la libertad, para llegar a proponer que, visto desde cierta perspectiva, el proceso de formación de un sacerdote tiene que apuntar a una profunda liberación, de modo que pueda cumplir con un ministerio liberador, cuyo significado es necesario explorar.

La vida de Jesús es siempre, a los ojos de los cristianos, un mapa que ha de ser descifrado. Sus palabras y sus actitudes aparecen con frecuencia como contradictorias si no tenemos en cuenta el contexto, la globalidad de su misión. Por ejemplo, nos dice: «No creáis que vine a suprimir la Ley o los Profetas... Os aseguro que primero cambiarán el cielo y la tierra antes que una coma de la Ley» (Mt 5, 17-18). Y al mismo tiempo, Jesús insistentemente marcó sus diferencias con las autoridades cívico-religiosas oficiales, a las que interpeló con dureza transgrediendo constantemente normas y costumbres (Mc 3, 1-6; Mc 7, 1-13; Mc 11, 27-33; Lc 5, 27-32; Lc 6, 1-11). Jesús es radical y sorprendente en este punto (Lc 9, 57-62; Mt $10,34-39$ ) y parece no sentir culpa de hacer lo que hay que hacer, aunque no esté bien visto: por ejemplo cuando les causa preocupación a sus padres al permanecer en Jerusalén durante la peregrinación (Lc 2, 41-52); cuando expulsa a los mercaderes del Templo en una acción violenta e inusitada (Mt 21, 12-13).

Jesús no aparece como un personaje austero y sufriente, obsesionado con el trabajo y cuyo norte es eso que llamamos hoy «fuerza de voluntad». Jesús es un hombre abierto, cercano, compasivo, muy humano; no tiene reparos para vincularse con todo tipo de gentes, lo que ciertamente le trajo más de un problema (Mt 9, 9-13; Jn 4, 6-9). El término fariseo, por el contrario, significa «separado». No se los podía tocar, vivían aislados, «no contaminados». Despreciaban a aquellos que estaban metidos en asuntos «mundanos». Es a ellos a quienes Jesús les dice que el celo por la Ley los ha alejado de Dios (Mc 7, 1-8; Mt 12, 1-14; Mt 23, 13-36).

El que se somete a la Ley vuelve a la servidumbre, dice san Pablo, y no debemos ser hijos de la servidumbre porque el Evangelio releva a la Ley. Ya en la carta a los Romanos, quizás todavía en una elaboración de lo que 
ha sido su propio proceso de conversión, san Pablo comienza a acercarse a lo que vendría a ser un paso teológico fundamental: muestra cómo la venida de Jesús libera al hombre no sólo del pecado, sino también de la Ley (Rom 3, 27-29). Luego, en la carta a los Gálatas es explícito al desarrollar este punto: «Por el camino de la Ley nadie llega a ser justo a los ojos de Dios» (Gal 3, 11); "Cristo nos rescató de la maldición de la Ley» (v. 14); "Cristo nos liberó para que fuéramos libres. Por eso, manteneos firmes y no os sometáis de nuevo al yugo de la esclavitud. Yo Pablo os lo digo, si os circuncidáis, Cristo no os servirá de nada. De nuevo lo declaro tajantemente: Todo aquel que se deja circuncidar, queda obligado a cumplir toda la Ley. Ya no tenéis que ver con Cristo quienes tratáis de ser justos practicando la Ley; os habéis apartado de su gracia» (Gal 5, 1-5). En fin, Cristo nos despertó para gozar de la libertad de los hijos de Dios.

El mismo Jesús, dialogando con algunos que lo seguían, anuncia que la libertad será el eje de esta Nueva Alianza: «...conocerán la verdad, y la verdad los hará libres. Respondieron: Somos hijos de Abrahán y nunca hemos sido esclavos de nadie, ¿por qué dices que llegaremos a ser libres? Jesús contestó: En verdad, en verdad os digo, el que comete pecado es esclavo del pecado. Pero el esclavo no quedará siempre en la casa; el Hijo, al contrario, está para siempre en ella. Si el Hijo os hace libres, vosotros seréis realmente libres» (Jn 8, 32-36).

El Evangelio le abre a la humanidad la posibilidad de un salto en su evolución. Esto ya es claro en las palabras de Jesús: «Con Juan Bautista terminaron los tiempos de la ley y los profetas» (Mt 11, 13). La Ley no puede justificar ni guiar al cristiano, sino la fe y el Espíritu. Hay que dejarse llevar por el Espíritu, eso es actuar correctamente. Sin embargo san Pablo, que asienta esta doctrina, era un asiduo helenista, le parecían intolerables los excesos, le gustaba la continencia, el equilibro y el justo medio, y al espíritu lo ubica en oposición a la «carne». Es decir, aproxima el Evangelio a una ética griega de la virtud, lo que de todos modos se acerca más a una ética que hoy llamaríamos del desarrollo personal, diferente de una ética colectiva fundada en la norma social consagrada consuetudinariamente, o resguardada por algún grupo. Esto es tan evidente que siglos más tarde, Tomás de Aquino señala en la Suma teológica que ninguna autoridad humana, ni siquiera el magisterio de la Iglesia, puede sustituir a la conciencia personal. Sea como fuere, por ahora lo importante es hacer notar que en san Pablo hay una cierta ambigüedad; por una parte apuesta a lo que hoy llamaríamos la «fuerza del yo» para controlar las pasiones, y por otra, a la entrega total, del yo incluso, en un gesto de humildad y de confianza 
radical que nos conduce por otro camino que el de una vida correctamente apegada a las reglas, aunque no sea contradictorio con ella.

Como veremos, si creemos que la invitación de Jesús a todo cristiano se dirige a alcanzar la libertad que nace del Misterio pascual, aceptando la gratuidad del amor de Dios -aquello que san Pablo destaca como «escándalo para los judíos y necedad para los griegos» (1 Cor 1, 22)-, el papel del sacerdote, más que enseñar la Ley y velar por su cumplimiento -que muchas veces se traduce en la observación de las normas que en ese momento histórico y para determinado grupo son las correctas-, es el ayudar a los cristianos a superar el miedo a la Ley, y a acompañarlos en el proceso de aprender a vivir de otra manera.

\section{b) El anonadamiento es respuesta vocacional}

Tanto el nacimiento de Jesús (la encarnación), como su muerte (la crucifixión), representan dos de los misterios capitales del cristianismo, que mantienen su vigencia perturbadora, que han sido fuente de intensos debates teológicos desde hace dos mil años.

Ahora conviene que nos preguntemos por el significado psicológico y pedagógico de la encarnación y de la crucifixión, para poder transferirlo a una experiencia de formación como es la del Seminario. Al respecto, san Pablo nos ofrece palabras decisivas en la carta a los Filipenses: «Tened los mismos sentimientos que tuvo Cristo Jesús: Él, que era de condición divina, no se aferró celoso a la igualdad con Dios, sino que se rebajó a sí mismo hasta ya no ser nada, tomando la condición de esclavo, y llegó a ser semejante a los hombres. Habiéndose comportado como hombre, se humilló y se hizo obediente hasta la muerte, y muerte en una cruz» (Flp 2, 5-8). Aunque san Pablo ofrece este párrafo en el contexto de lo que debe ser una comunidad cristiana, es indudable que tiene consecuencias directas para la formación sacerdotal.

En casi todas las tradiciones religiosas se incluye la idea del «viaje místico», que comienza con una purificación. En el caso del Evangelio, esto lo encontramos en el viaje de Jesús al desierto y en las tentaciones que allí sufre, que si las observamos atentamente, no son sino el engrandecimiento del yo. «Si eres hijo de Dios di que estas piedras se conviertan en panes», reclama el Demonio (Mt 4, 1-4). Jesús tiene hambre, pero Satanás no prepara para él un banquete, sino que lo desafía en su orgullo: demuestra quién eres. Esa es verdadera tentación: «eres».

Si la libertad cristiana pasa por la muerte, entonces pasa por el vértigo del no ser. Si el sacerdote es libre como Cristo lo fue, libre de patrones, de 
modelos, de reglas externas, es porque se sostiene no en la Ley, sino en la fortaleza que proviene de la Gracia divina. El sacerdote, como cualquier discípulo de Jesús, no puede dejar de oír una y otra vez: «El que me siga, que lo deje todo» (Lc 14, 33). Es su invitación al desprendimiento, a vaciarse en último término. Se trata de una llamada a dejar de gozar en los mitos personales que nos sostienen, es una invitación a vaciarse de las identificaciones, del narcisismo; es dejar espacio para que la Gracia actúe. En ese proceso se puede conocer el auténtico amor, el amor que hace libre al que ama y al que es amado.

El misterio de la muerte y resurrección de Jesús puede ser leído como el paso inevitable de la semilla que muere para poder dar frutos, es la muerte como experiencia de pasaje a otro estado. Esto es tan interpelante, que Dios suelta en algún minuto a su Hijo, lo deja a la intemperie, a merced del sinsentido, que es lo que leemos del grito angustioso: «por qué me has abandonado» (Mt 26, 46). Es posible que ese grito contenga el núcleo central del misterio evangélico.

Si todo cristiano está invitado a morir a sí, con mayor razón, el proceso de formación sacerdotal debería ser en alguna medida un desmontaje de sí, de lo que hemos llegado a ser, un proceso de vaciamiento, para dejar lugar a la Gracia, y a la acción del Espíritu. Un sacerdote es alguien que tiene que ser capaz de oír serenamente, de no temer a las dudas, a la angustia del otro. Predicar y curar, esas son las tareas encomendadas por Jesús a los apóstoles, quien a su vez dedicó gran parte de su misión a sanar. Para ello, hay que tener espacio en el alma, en la mente, un hueco donde acoger al otro.

$Y$ sin embargo, nos encontramos con todo lo contrario, pues un cierto número de seminaristas buscan estatus social. Qué diferente a lo que uno esperaría de alguien que hubiese comprendido las palabras de Jesús: «Te bendigo, Padre, porque has ocultado esta verdad a sabios y poderosos y la has revelado a los pequeños» (Mt 11: 25). Ser sacerdote está muy lejos de representar un papel, un rol. No se trata de entrenar a un actor. Jesús incluso les cambiaba el nombre a sus discípulos, o sea, los despojaba de aquello que es lo más propio de una persona, el corazón de su identidad. Pero no trató de convertirlos en una colección de virtudes, de homogenizarlos, ni de urbanizarlos. Les prometió el Espíritu. Es el dilema de la educación de un sacerdote: el elemento nuclear, la conversión, que si bien no invalida la formación profesional y la socialización, lo sitúa todo en otro plano.

En el Evangelio encontramos muchas veces a Jesús diciendo frases que apuntan hacia la idea del despojamiento, del abandono como la clave 
del camino cristiano: «El que quiera seguirme, que renuncie a sí mismo, que cargue con su cruz y que me siga. Pues el que quiera asegurar su vida la perderá y el que la pierda por mí la hallará» (Mt 16, 24-26); «Si alguno quiere venir a mí, y no deja a un lado a su padre, a su madre, a su mujer, a sus hijos, a sus hermanos, a sus hermanas, $y$ aun a su propia persona, no puede ser mi discípulo» (Lc 14, 25-33); «Felices los que tienen espíritu de pobres, porque de ellos es el reino de los cielos» (Mt 5, 3). En un gesto que podría aparecer ante nuestros ojos como cruel, «a otro le dijo: Sígueme. Este le contestó, permíteme ir primero a enterrar a mi padre. Pero Jesús le dijo: Deja que los muertos entierren a sus muertos, tú anda a anunciar el reino de Dios. Otro le dijo: Te seguiré, señor, pero permíteme que me despida de los míos. Jesús entonces le contestó: Todo el que pone la mano en el arado y mira hacia atrás, no sirve para el reino de Dios» (LC 10, 59-62). Mirar atrás puede ser entendido como tener dificultades para desprenderse del pasado, como nostalgia, y de hecho esto es algo que aparece como uno de los mayores obstáculos para entrar al Seminario. Los formadores deberían tener gran lucidez para hacer frente a esto, y velar porque las renuncias que un seminarista debe hacer para continuar el camino del sacerdocio no sean suplidas por el engrandecimiento de la propia persona.

¿Qué significa negarse a sí mismo y tomar la propia cruz? ¿Frenar las propias pasiones? (¿No eran acaso Jesús y varios de sus apóstoles sumamente apasionados?). ¿Ese es el sentido de la mortificación, tratar de autoinfligirse privaciones e infelicidad? Puede ser. Pero son posibles otras lecturas mucho más decisivas e interesantes; según estas, lo que significa morir es tomar distancia de sí mismo, desprenderse de sí, vaciarse del ser propio.

Todos los ejercicios espirituales, las reglas o los esfuerzos ascéticos no tienen ningún sentido si no están atravesados por el misterio de la muerte y la resurrección de Cristo, culmen de la encarnación. Lo mismo que toda tarea caritativa o de promoción humana. Toda vocación se enfrenta en algún minuto a una bifurcación, se abren dos caminos: el que lleva a reforzar -con muy buenas intenciones, y muchas veces con buenas acciones- el propio narcisismo y dejarse apuntalar ortopédicamente por reglas; o por el contrario, el camino de la libertad, que pasa por el vértigo del vacío y por la entrega a la acción del Espíritu Santo. No son cosas que aparezcan necesariamente como opuestas, pero son de niveles diferentes. Sólo así se entienden las aparentes contradicciones en el mensaje de Jesús. 
La verdadera diaconía supone no hablar de sí y para sí. La labor del sacerdote en tanto autoridad también se ve cuestionada por la invitación a negarse a sí mismo. Sin este elemento no es comprensible la noción de autoridad como servicio. En el Evangelio encontramos que se dice de Jesús: «Enseña como quien tiene autoridad, al contrario que los maestros de la ley» (Mc 1, 22). Jesús no detenta ninguna autoridad formal, no tiene cargo alguno en virtud del cual exigir.

En diversos pasajes del Evangelio encontramos a Jesús advirtiendo que él no ha venido a ser servido sino a servir, actitud que reclama a su vez a sus discípulos. Jesús subvierte las jerarquías (Mc 10, 42-45; Lc 18, 9-14). Jesús no impone, no intimida, y rara vez manda o reprende. Es respetuoso de la libertad de los otros. En la traducción griega de la Biblia, Jesús no dirige hacia los hombres el verbo epitiman, que significa ordenar, mandar, exigir; lo reserva para los demonios. Más aún, Jesús le señala a sus discípulos «no prohibáis» (Mt 19,14; Mc 9, 39; Lc 9, 50).

\section{c) La gratuidad del amor de Dios}

El sacerdocio y su actividad ministerial tienen peso por sí mismos, como una forma de la invitación que el Evangelio hace a todos los hombres. Se quiebra sin el testimonio honesto y se desaprovecha si no sabe qué hacer ante las nuevas circunstancias históricas, pero su esencia está en el abandono a Dios, en la forma de respuesta a ese amor primero de Dios, mayor, gratuito y sobreabundante, que permite llegar a guiar a otros en ese camino de dejarse tomar por Él.

La Gracia, si bien aparece en el Antiguo Testamento, se utiliza más bien para caracterizar el nuevo régimen instaurado por Cristo, oponiéndolo a la "economía» antigua: ésta estaba regida por la Ley, aquélla lo está por la Gracia. Y si el amor de Dios es gratuito, eso no puede sino tener consecuencias en la formación y en el ministerio sacerdotal.

\section{RASGOS DEL CANDIDATO EN LA FORMACIÓN SACERDOTAL}

Teniendo en cuenta lo expresado antes, me atrevo a señalar algunos rasgos que pueden diseñar el desarrollo del proceso formativo. El perfil necesario a nuestro tiempo parece exigir: 1) candidatos con una inconfundible personalidad, en el fondo y en las formas; 2) suficiente capacidad de alteridad para relaciones humanas positivas (personas abiertas para la misión); 3) una adecuada identidad vocacional, sin vínculos o dependencias de grupos particulares que tiendan, de modo implícito o explícito, a poner la perte- 
nencia diocesana en segundo lugar, y 4) una clara opción por el sacerdocio diocesano secular. En esto no se trata de una devoción particular, sino de una consciente y explícita integración al clero diocesano secular, como un verdadero bien de la Iglesia. La doble pertenencia introduce en una tensión personal y social que sitúa en la tensión de lo contradictorio. La ambigüedad en cualquiera de estas cuatro dimensiones tiende a ser un factor de confusión con incidencia negativa en el corazón del proceso formativo. Sin una libre y plena confianza en el Seminario, éste resulta problemático en su vida comunitaria e inútil para el logro de sus fines. No en vano, la ambigüedad llega a formar parte de la estructura de la personalidad, y hace personas inadaptadas y divididas. La calidad humana y espiritual es requisito necesario: La cantidad de seminaristas sin adecuada selección es engañosa y fuente de futuros conflictos. Deteriora a los sacerdotes en su vida personal, en las relaciones mutuas y en la acción pastoral.

Finalmente, es necesario subrayar la necesidad de optar por el Seminario como cauce de la respuesta a la llamada del Señor; asumir un proceso educativo integral, inspirando en el seguimiento a Jesucristo, que tiende a la maduración de la persona. Comprende las cuatro dimensiones formativas descritas en Pastores dabo vobis y en la nueva Ratio, arraigadas en una sincera vida espiritual, de conversión e identificación con Cristo.

\section{a) Perfil educativo}

No es fácil dibujar el ideal de un sacerdote capaz de perseverar creciendo en madurez humana y cristiana y en adaptación apostólica para el hombre de nuestro tiempo. La evolución es rápida, los principios son los mismos, pero su plasmación concreta en jóvenes de hoy y para hoy pide realismo y adaptación. Quizás sea más fácil saber lo que no se quiere. Por esa vía se despejan los obstáculos para que florezca lo normal y lo posible. Al menos es necesario saber lo que no se quiere, comenzando por el número indiscriminado. La vocación es personal y el ministerio lo ejerce la persona concreta. La idoneidad y la recta intención es de cada uno. El número no sustituye a la singularidad de la persona. En este supuesto, es evidente que los criterios de la Iglesia, expresados en sus orientaciones, son de obligada referencia.

Podemos tener a la vista las siguientes fuentes:

1) Las deficiencias o carencias del clero actual para evitarlas, en lo posible, en el futuro.

2) Las posibilidades y deficiencias que aparecen en los seminaristas actuales. 
3) Los problemas de conducta y de sentido que se observan en las nuevas generaciones, por ejemplo, la inmadurez e inestabilidad en los matrimonios, las carencias afectivas y educativas en muchos adolescentes, el poder de la ideología de género, etc.

Estas tres fuentes advierten de lo que se ha de evitar y abren el camino que se ha de alumbrar.

\section{b) Armonía entre edad psicológica y cronológica}

Un dato significativo sobre la madurez humana proviene de la armonía entre la edad psicológica y la edad cronológica en relación con el desajuste ante el sentido de la realidad y el funcionamiento equilibrado de la personalidad: la distorsión entre objetividad y subjetividad, insuficiente percepción objetiva de sí, con tendencia neurótica, insuficiente capacidad de alteridad, con posible egocentrismo que también distorsiona el sentido de la responsabilidad; una cierta rigidez mental y emotiva que dificulta la evolución de la educación, presentando resistencia al cambio, afincado en posiciones y hábitos paralizantes.

c) Idoneidad, recta intención y buena voluntad

El objeto del discernimiento se centra en la idoneidad y la recta intención del candidato. Dios llama a través de las cualidades de naturaleza y gracia, por un lado, y de los signos verificables de recta intención, por otro. La recta intención se expresa por la implicación sincera en la respuesta a la llamada: los datos que reflejan la experiencia concreta de implicación. Estas dos cosas son las que hay que discernir a través de los datos que aparecen en el camino. Dos cosas íntimamente unidas: se puede tener cualidades sin voluntad de responder y se puede querer la llamada sin capacidad para responder.

\section{d) El diálogo en el discernimiento}

Este diálogo es imprescindible situarlo en la más estricta objetividad, lejos de cualquier impresión de subjetivismo. El discernimiento vocacional pretende buscar y obedecer la voluntad de Dios. No se trata de merecer, premiar o castigar. La cuestión es estrictamente objetiva. No se reduce a una relación de autoridad/obediencia, sino de fidelidad a la verificación de los requisitos necesarios. También se ha de tener presente que el discernimiento no se puede predeterminar, no se puede pretender el resultado que uno desea, sin más. Entonces no sería discernimiento. 
e) Autonomía del ritmo del camino formativo sacerdotal

El camino formativo sacerdotal es personalizado, cada uno sigue su ritmo. De ahí se deduce la necesaria distinción entre el ritmo de los estudios académicos y el ritmo formativo adecuado a cada caso. No sería lógico afrontar las posibles carencias formativas si, al mismo tiempo, el alumno prosigue la totalidad de los estudios con el resto de sus compañeros. Esto también podría parecer, equivocadamente, que se trataría de un simple freno vacío de sentido, vacío de contenido formativo.

Al acomodar el ritmo formativo a cada uno, sobre todo en el caso de repetir el año de formación, también será necesario elaborar alguna programación adaptada a las necesidades concretas del candidato. Y, en consecuencia, modular el número de asignaturas del currículo académico que va a cursar, en función de las necesidades de su ritmo formativo.

\section{LA VIDA EN EL SEMINARIO}

El fin específico de la educación del Seminario se diferencia de otros ámbitos de formación. Tiene su propia configuración. El Seminario ha de responder, en su método y género de vida, a lograr los fines educativos propios al camino vocacional. A saber, desarrollar las cualidades requeridas, ya discernidas en el momento de la admisión, y promover la madurez de la conducta como lenguaje de la recta intención. No es una residencia de estudiantes. Es un ámbito inspirado en los valores evangélicos, con un género de vida que facilite la armonía y serenidad de la personalidad humana y cristiana, y un camino de vida interior y fraterna que, al mismo tiempo, desarrolle las cualidades espirituales y las relaciones humanas. No es una residencia de estudiantes donde la educación del sentido de la responsabilidad se deja a merced de la sola espontaneidad. Implica una disciplina de vida personal y comunitaria bien definida y evaluable. Un género de vida que armonice la libertad con el deber y la fidelidad. El respeto a la libertad no es permisividad ni indiferencia, sino respeto al protagonismo de la conciencia recta, referida al deber ser y hacer.

Si se pretende el crecimiento de personas adultas se precisa que la forma de vida sea adulta, es decir, fundada en valores humanos y cristianos que favorezcan el sentido de la responsabilidad y el espíritu de servicio evangélico como lenguaje de madurez.

Existen dos elementos clave que sostienen todos los criterios que a continuación se van a enunciar, a saber: el dialogo formativo y la implicación personal de cada seminarista. 
En cuanto a la importancia del diálogo formativo, se debe decir que el Seminario es el lugar de la iluminación, purificación, transformación y unión a Dios. Esto es posible desde la sencillez de corazón, la confianza y la transparencia. No hay educación sin sinceridad y confianza en el diálogo formativo. La educación se sostiene en la apertura de sí mismo, sin miedo a la verdad. La verdad libera y la mentira traiciona. La impermeabilidad anula la pretensión educativa. Si fuera el caso, no es posible proseguir sin superar el repliegue ante lo nuclear del proceso formativo personalizado. Se requiere una fluida y regular relación eficiente con el formador y con el director espiritual.

En relación a la implicación personal, la formación tiene que desarrollar una conducta de crecimiento en asertividad, o sea, de comunicación vital en la verdad, dejando a un lado la pasividad o la agresividad. Se trata de un modo de vivir en una existencia que se desarrolla de modo consciente, congruente, directo y equilibrado. Sin la viva implicación del sujeto no hay educación, ni de la mente ni del corazón, ni de la voluntad ni del actuar. Se ha de vivir una disciplina personal de purificación, dominio de sí y crecimiento integral, que vaya encauzando las motivaciones nacidas de la fe, la obediencia como respuesta a la llamada y el cumplimiento del deber como lenguaje de la recta intención.

Algunos criterios pueden ser:

1) La conducta: Manifestación de un desarrollo del carácter con signos de serenidad que llevan a una situación de «equilibrio de juicio y comportamiento» (OT 11).

2) Sociabilidad: Normalidad para establecer relaciones humanas gratificantes que inciden en el ambiente de la comunidad formativa del seminario. La sociabilidad es razón de objetividad frente a los subjetivismos o infantilismos, facilitando siempre el encuentro y el dialogo, desde «relaciones humanas de serena amistad y profunda fraternidad» (PDV 43).

3) Coherencia: Grado de correspondencia entre lo que se dice y lo que se hace. Capacidad de sinceridad consigo mismo y con los demás. Se traduce en la «educación para amar la verdad, la lealtad, la fidelidad a la palabra dada» (PO 3).

4) Apertura al cambio: Disponibilidad para vivir en el descubrimiento de nuevas actitudes que vienen a reforzar el desarrollo de la formación. Se propicia el crecimiento cuando se asumen las crisis, confrontándolas con la propia existencia en orden a alcanzar una síntesis que siempre es llamada a avanzar. 
5) Conciencia recta: Grado de aproximación entre la conciencia y la conducta moral y creyente. Esto exige la práctica del juicio moral sobre sí mismo, evitándose el vivir desligado de referencias, en doblez. «Es el don que brota de sí mismo, como camino y contenido de la auténtica realización personal» (GS 24).

6) Perfectibilidad en los dinamismos afectivos: Implicación en la propia madurez afectiva e identidad sexual. Grado de normalidad de las relaciones afectivas en su ámbito familiar y de la expresión en formas externas. Identidad emocional (lo que le enfada, pone nervioso, distrae y descentra; lo que le agrada, estimula y le ayuda a fijar la atención); advertir sus gustos y sus disgustos; asumir su identidad sexual de hombre-joven llamado al celibato interior y exterior; describir la influencia de la familia y del entorno amical, así como la factibilidad de crecimiento y mejora de los rasgos propios de su entorno; vivir con generosidad las relaciones cercanas; saber establecer lo prioritario-esencial, lo urgente, lo necesario y lo prescindible; desarrollar una identidad sentimental-pulsional equilibrada con capacidad de relaciones adultas no posesivas; tener un sano tono vital (alegría, respuesta proporcionada ante las adversidades, responsabilidad a lo encomendado, entrega progresiva y desapego maduro).

7) Dedicación al estudio: El estudio y su dedicación configura la personalidad. No se trata de una dimensión extrínseca y accesoria. De modo particular, el estudio de la filosofía debe llevar a un conocimiento más profundo de la persona, de su libertad. También la filosofía permite descubrir la relación con los misterios de la salvación que serán presentados en la teología. El estudio no es «una pura ciencia nocionística, sino que lleva en el proceso de formación a la inteligencia del corazón para en el futuro comunicar el misterio de Dios a los hombres» (PDV 51). Es importante desarrollar el apetito por la lectura como medio de crecimiento personal.

\section{EL PROCESO FORMATIVO: DINAMISMO DE LA IDENTIDAD EN LA COMUNIDAD DEL SEMINARIO}

Finalmente, puedo expresar que el proceso formativo en la comunidad del Seminario se desarrolla en la medida que cada seminarista asume que su vocación crece siendo peregrino en la propia conversión, motivado por una fuerte experiencia de oración que se alimenta en la mistagogía de la fe.

El seminarista es peregrino en la propia conversión a partir de la conciencia de sí y de la apertura a las manifestaciones del Señor, iniciado en un camino abierto al examen y al cambio en relación con lo que provoca 
el encuentro con la Palabra de Dios, con el testimonio de otros y con la propia experiencia íntima de interioridad. El camino de la conversión se inicia cuando el corazón se vuelca con confiada esperanza hacia Jesús, Camino, Verdad y Vida. La vida entra en la dinámica del cambio. Desde entonces se camina en pos de Jesús. Se recorre el camino de la fe, que es camino de conversión por el amor. ¿Qué signos nuevos se dan en mi vida que indican este camino de conversión?

Una suficiente experiencia de la vida de oración, tras los años de formación. Práctica de la Lectio divina o de otros métodos de oración: valoración positiva de la experiencia de oración. Si aún no se ha logrado una suficiente experiencia de interiorización para vivir el encuentro de fe con el Señor, presente en la oración, será oportuno prestar una atención más explícita y personalizada para superar este obstáculo. Si durante la formación sacerdotal se relativiza la oración, es previsible dudar de un futuro satisfactorio. De algún modo, el abandono de la oración puede ser, en la práctica, abandono de la fe y ¿de la vocación?

Alimentar la vocación en la mistagogía de la fe; es necesario situarse en el núcleo mismo de la espiritualidad litúrgica, en el misterio pascual, en la espiritualidad bautismal, superando las formas externas y entrando en la vivencia interior. El misterio de Cristo es el corazón de la vida litúrgica, es lo primero, lo central. Es necesario haber entrado y participar en la espiritualidad del tiempo litúrgico, que marcará el camino durante toda la vida sacerdotal. 